\title{
May 2001
}

\section{EVALUATE EFFECTS OF HYDRAULIC TURBULENCE}

ON THE SURVIVAL OF MIGRATORY FISH

DESIGN AND CONSTRUCTION OF EXPERIMENTAL APPARATUS TO STUDY THE POTENTIAL EFFECTS OF TURBULENCE ON FISH

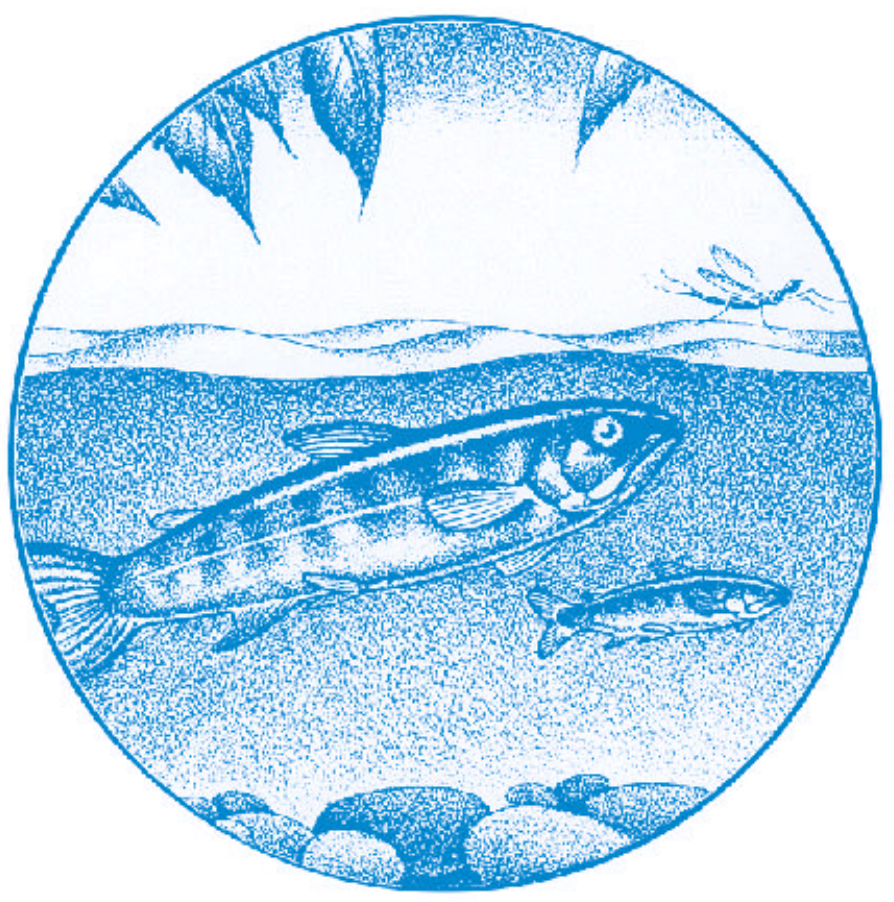

DOE/BP-26531-2 
This report was funded by the Bonneville Power Administration (BPA), U.S. Department of Energy, as part of BPA's program to protect, mitigate, and enhance fish and wildlife affected by the development and operation of hydroelectric facilities on the Columbia River and its tributaries. The views of this report are the author's and do not necessarily represent the views of BPA.

This document should be cited as follows:

Odeh, Mufeed - U.S. Geological Survey-Biological Resources Division, Evaluate Effects of Hydraulic Turbulence on the Survival of Migratory Fish, Design and Construction of Experimental Apparatus to Study the Potential Effects of

Turbulence on Fish, Report to Bonneville Power Administration, Contract No. 2000AI26531, Project No. 200005700, 9

electronic pages (BPA Report DOE/BP-26531-2)

This report and other BPA Fish and Wildlife Publications are available on the Internet at:

\section{http://www.efw.bpa.gov/cgi-bin/efw/FW/publications.cgi}

For other information on electronic documents or other printed media, contact or write to:

Bonneville Power Administration

Environment, Fish and Wildlife Division

P.O. Box 3621

905 N.E. 11th Avenue

Portland, OR 97208-3621

Please include title, author, and DOE/BP number in the request. 


\title{
Evaluate Effects of Hydraulic Turbulence on the Survival of Migratory Fish
}

Design and Construction of Experimental Apparatus

to Study the Potential Effects of Turbulence on Fish

Prepared by:

Mufeed Odeh

U.S. Geological Survey-Biological Resources Division

S.O. Conte Anadromous Fish Research Center

One Migratory Way

P.O. Box 796

Turners Falls, MA 01376

Prepared for:

\author{
U.S. Department of Energy \\ Bonneville Power Administration \\ Division of Fish and Wildlife \\ P.O. Box 3621 \\ Portland, OR 97208
}

Project Number 2000-057-00

Contract Number 00 AI 26531

May 2001 


\section{Design and Construction of Experimental Apparatus to Study the Potential Effects of Turbulence on Fish}

\section{Introduction}

This report presents the completed design and construction process, and working details, of the test apparatus for the turbulence project. As mentioned in the first progress report, this type of experiment has not been attempted previously. In addition, turbulence data in the tailrace of a power plant are not available for reference. We plan to generate turbulence intensities and scale based on representative flow velocities downstream of draft tubes as well as visual observations of flow conditions in a typical tailrace area. Various combinations of nozzles will be used to generate mixing inside a large tank cavity, referred to herein as the turbulence chamber. The turbulence chamber was made with steel frame and clear acrylic sides and bottom. The clear sides and bottom will facilitate viewing and videotaping from outside. Nozzle velocities and water surface profiles will be accurately monitored with calibrated flow measurement devices to insure repeatability of the hydraulic conditions during biological testing.

\section{Experimental Apparatus}

The 'turbulence chamber' comprises mainly a large area, measuring 4 feet wide by 10 feet long by 4 feet deep (122 cm wide x $300 \mathrm{~cm}$ long x $122 \mathrm{~cm}$ deep), filled with water where fish can be exposed to different flow regimes. Water supply is via a flow introduction manifold and individual supply pipes, flow control valves, and nozzles. An adjustable control gate to the exit channel controls water level inside the chamber. The large unobstructed area inside the chamber simulates a tailrace downstream of a hydropower turbine (Figure 1). A smooth inclined screen is located at the downstream end of the chamber. An arched aluminum frame, arching from one side of the chamber to the other, structurally supports the screen. Arching the screen in the horizontal and vertical planes eliminates sharp corners that may be used as sanctuaries by the test fish within the chamber. The arching of the screen also makes the chamber hydraulically smooth; by reducing corners that cause turbulent eddies and stagnation zones. The screen will be initially installed at $45^{\circ}$ to the vertical. The angle of inclination of the frame 
and screen is adjustable. Steeper screen angles to the vertical help provide larger chamber size at the bottom. The main frame of the chamber was made of welded steel. The side and bottom were made of clear Plexiglas to facilitate non-intrusive observations and videotaping of the test fish from outside. The entire turbulence chamber will be kept inside an enclosure with a curtain to facilitate control of lighting and prevent disturbance of the test fish by human movement.

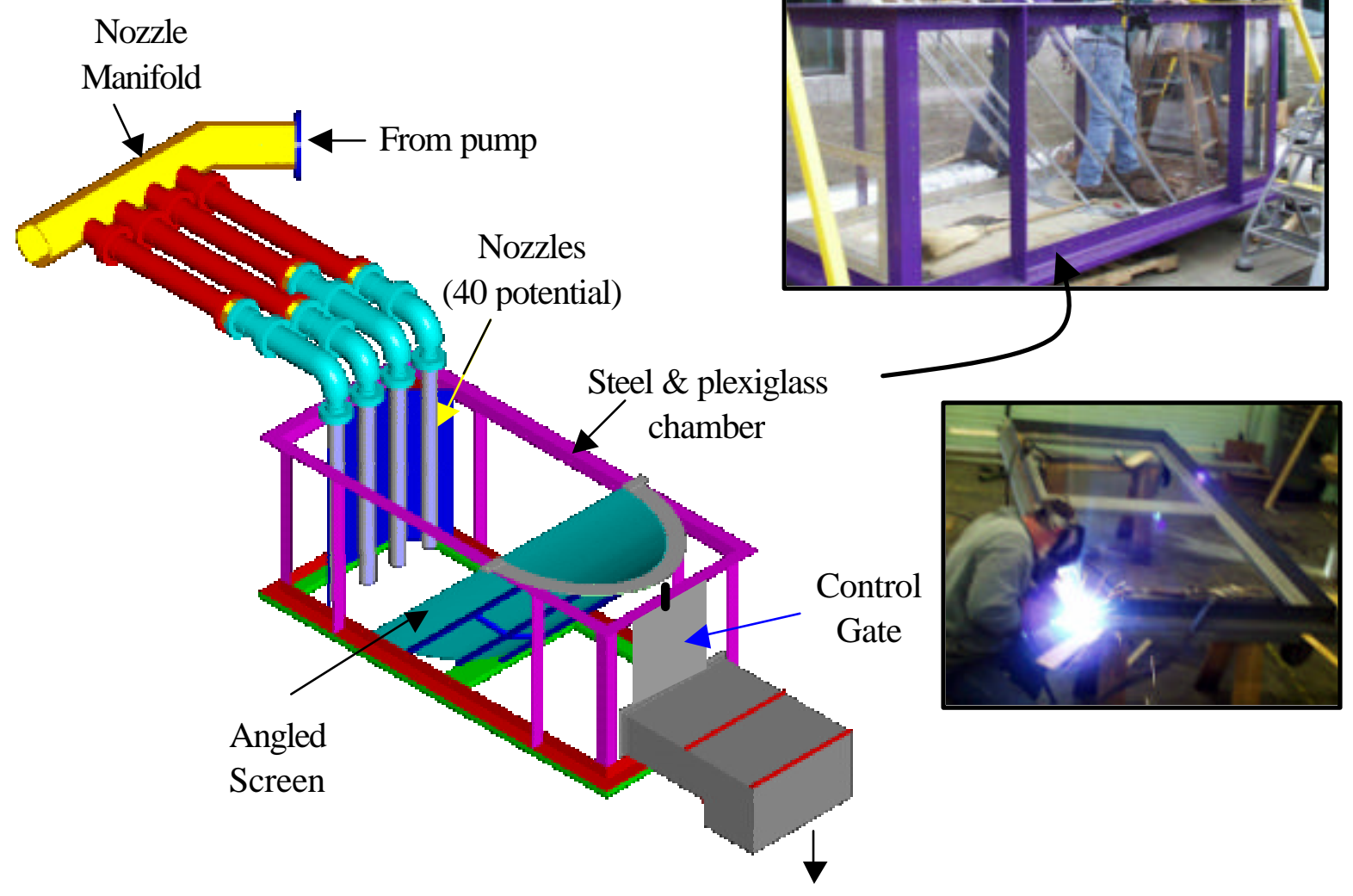

Back to sump

Figure 1. Experimental Apparatus for the "Potential Effects of Turbulence on Fish" study at the USGSConte Anadromous Fish Research Center, Turners Falls, Massachusetts. Insert photos show the main chamber under construction, 
The flow introduction arrangement is modular. Initially, flow will be introduced via an array of nozzles at the upstream end of the turbulence chamber. The varying number, size, and arrangement of flowing nozzles will be used to control turbulence intensity and scale. The largest number of nozzles is 40 (placed in rows of 4 horizontally and 10 vertically), and the largest nozzle size will be $3 / 4$ inch in diameter. The nozzles will be supplied with water via 4-inch diameter PVC pipes. The supply pipes and nozzles are isolated from the chamber by means of a smooth perforated screen, with the nozzles protruding through it (Figure 2). A mesh screen with large openings (smaller than the size of the test fish) will be placed in front of the nozzles to prevent striking the fish with the nozzle jets (large mesh screen is not shown).

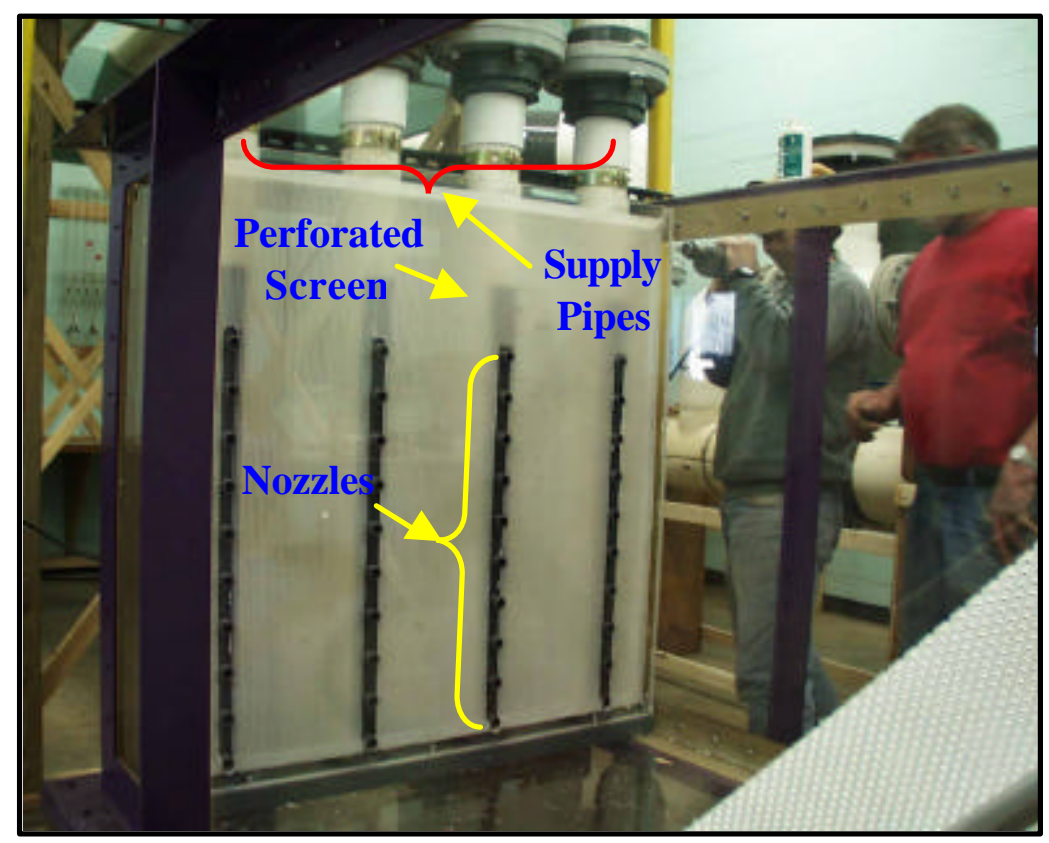

Figure 2. Flow introduction via nozzle arrangement; showing the 40 nozzles and a perforated screen used for fish exclusion from the supply pipes.

Water is supplied to the chamber via a 77 horsepower pump capable of delivering about $7 \mathrm{cfs}$ (cubic feet per second) at 68 feet of head (Figure 3a). The pump is located inside a $14 \mathrm{ft}$ wide by $32 \mathrm{ft}$ long by $14 \mathrm{ft}$ deep sump inside the hydraulic laboratory at CAFRC (Figure $3 b$ ). The chamber can also 
receive water from two smaller submersible pumps ( $2.8 \mathrm{cfs}$ at $40 \mathrm{ft}$ head each) located in the same sump. Figure $3 \mathrm{c}$ shows the piping used to convey the water from the sump pumps. The sump inside the hydraulic lab is filled with Connecticut River water via the Cabot Power Canal adjacent to CAFRC. Control valves located downstream in the pump discharge lines and near the nozzle supply lines are used to adjust the flow. An adjustable slide gate located at the end of the turbulence chamber controls the water surface elevation inside the chamber. Water is discharged back into the sump after passing through the chamber. Temperature, dissolved oxygen, and turbidity will be continuously monitored to maintain constant water quality throughout the experiments. The main water supply to the sump will be used for replenishment as needed.

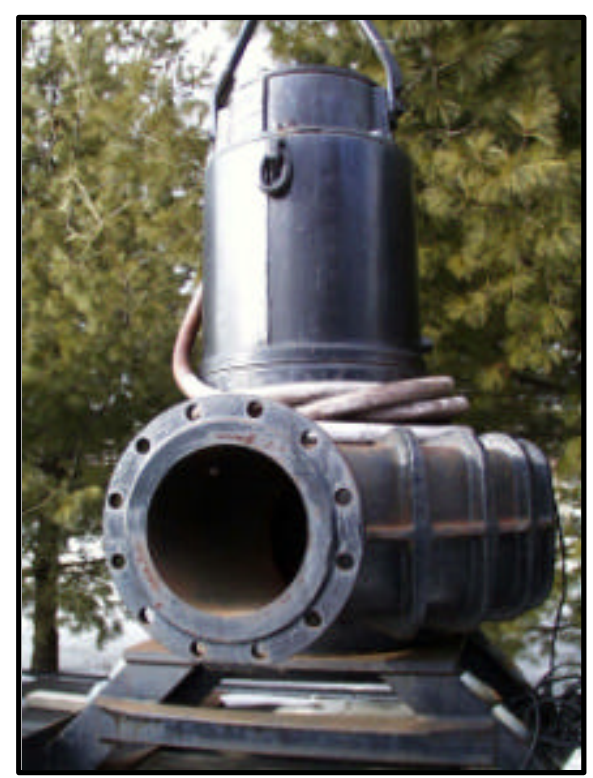

$\mathbf{a}$

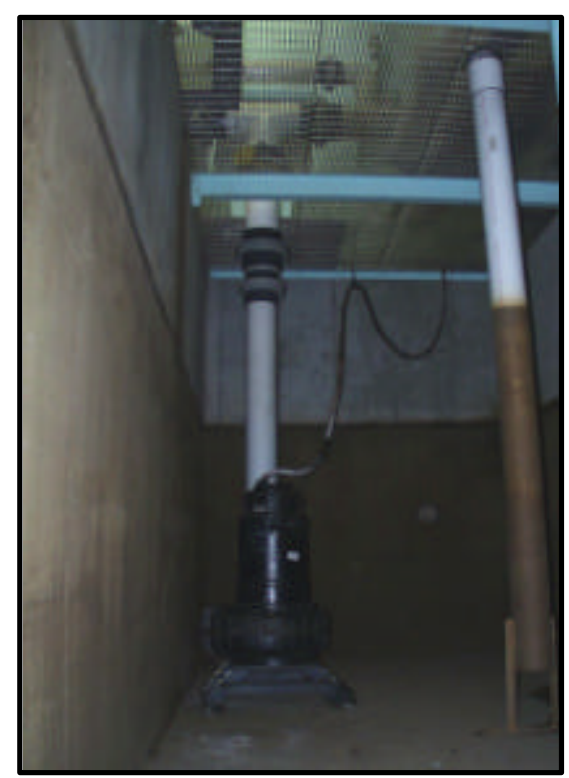

b

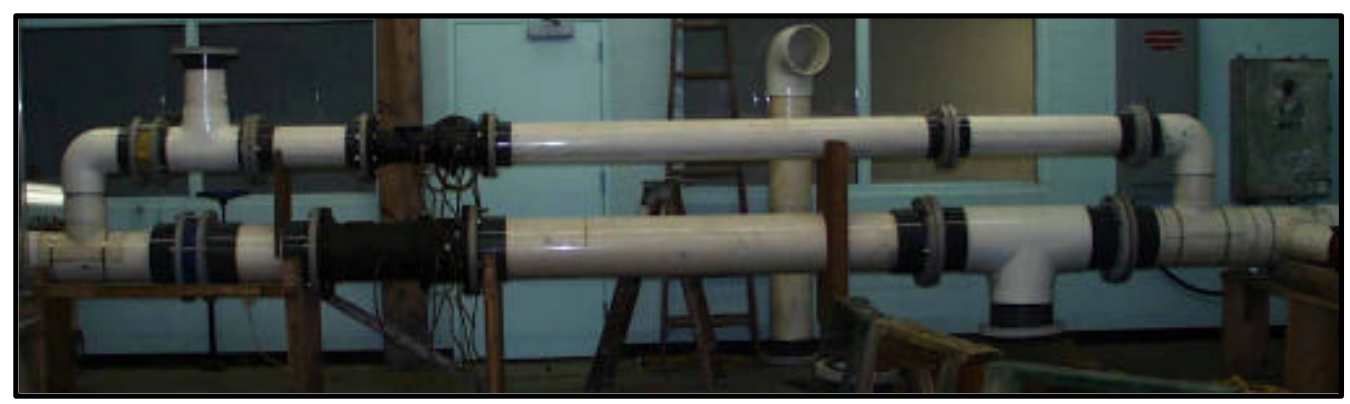

c

Figure 3. Photographs showing the sump pump, the sump, and the piping used to supply water to the turbulence chamber. 
Turbulence intensity at a point in the flow field is a measure obtained from statistical analysis performed on the instantaneous velocity measurements taken continuously for a period of time at that point. The top of the turbulence chamber will be outfitted with a rail system to support a carriage carrying two Acoustic Doppler Velocimeters (Model Sontek ADVLab). The carriage system will be motorized to accurately document different hydraulic test conditions at which fish will be tested. Water levels will also be documented by using a point gauging system.

The instantaneous velocity measurements will be taken points within a predetermined grid system within the chamber. The spacing of these points was chosen to be 2 in $(5 \mathrm{~cm})$, which was based on the size of the test fish of 6 in $(15 \mathrm{~cm})$. Inflow to the chamber will be documented by using calibrated Venturi flow meters (with $0.25 \%$ accuracy). This guarantees accuracy for repeatability of hydraulic test conditions with different groups of fish.

The design velocities for the nozzles arrangement are about $40 \mathrm{ft} / \mathrm{s}$, when all nozzles are open. Initial tests will be conducted with limited number of nozzles open to the flow. This will allow us to obtain considerably higher velocities. Also, the direction of the nozzles can be easily changed in the vertical, and therefore, varying degrees of swirl and scales of turbulence scales can be obtained. Calibration of the experimental setup is part of the next task. We will attempt to generate turbulence conditions with similar frequency and power spectra as those that occur in the tailrace area.

The photograph in Figure 4 shows the turbulence chamber in operation. In this "system shakedown" run all nozzles were left unobstructed and the chamber was filled to its capacity. The system is ready for calibration and testing. 


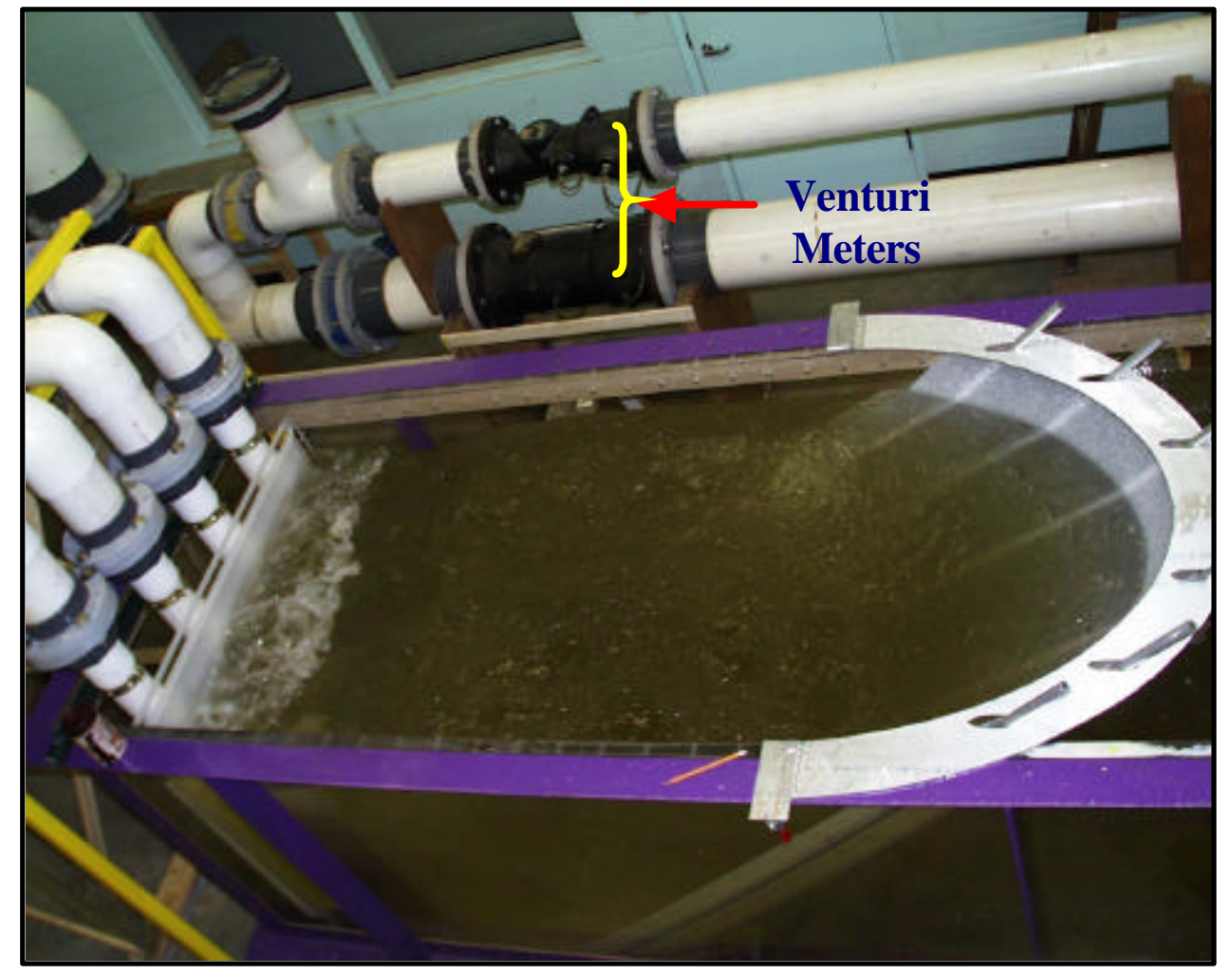

Figure 4. Photograph showing the turbulence chamber filled with water. 